letters

\section{TO THE EDITOR}

Please submit letters for the

Editor's consideration within three

weeks of receipt of the Journal.

Letters should ideally be limited to

350 words, and sent by email to:

Clinicalmedicine@rcplondon.ac.uk

\section{Chemotherapy-induced febrile neutropenia}

Editor - Marshall and Innes recently provided a useful review of the management and prevention of chemotherapy induced febrile neutropenia (Clin Med August 2008 pp 448-51).

Their comments, however, regarding timing of antibiotic administration could lead to confusion. On the one hand they suggest immediate and prompt administration of intravenous (iv) antibiotics but on the other they suggest that antibiotics can be given within two to four hours of diagnosis.

The Surviving Sepsis Campaign guidelines provide advice regarding antibiotic administration ie iv antibiotic therapy should be started as early as possible and within the first hour of recognition of septic shock (GRADE criteria 1B) and severe sepsis without septic shock (GRADE criteria 1D). ${ }^{1}$

I would suggest that every effort should be made to administer iv antibiotics as early as possible when patients present with sepsis or septic shock and that a two to four hour delay may not be acceptable.

PAUL TEMBLETT

Consultant in Intensive Care Medicine ABM University Hospital, Swansea

\section{Reference}

1 Dellinger RP, Levy MM, Carlet JM et al. Surviving Sepsis Campaign: International guidelines for management of severe sepsis and septic shock: 2008. Crit Care Med 2008;36:296-327.

\section{In response}

We fully support the comments made by Dr Temblett and agree that speedy resuscitation and iv antibiotic administration is essential in the severely ill patient as outlined in the Surviving Sepsis guidelines. Our comments were aimed at clinically stable patients where formal risk assessment with the Multinational Association of Supportive Care in Cancer index may define a significant proportion of patients eligible for alternative low strategies.

E MARSHALL Macmillan Consultant in Medical Oncology H INNES Consultant in Medical Oncology Clatterbridge Centre for Oncology, Bebington, Wirral

\section{Specialist diabetes services and acute-general internal medicine}

Editor - Specialist diabetes services should embrace a commitment to acute-general internal medicine. Winocour et al (Clin Med August 2008 pp 377-80) highlight the concern that the provision of care of specialist diabetes services is being increasingly compromised by a commitment to acute-general internal medicine services. This trend is reflected in work currently undertaken by consultants at Torbay Hospital: four diabetes and endocrinology consultants provide care on the acute general medical take rota and it is regularly necessary for clinics to be postponed so that on-call commitments can be met. In addition, there is the need for specialist registrars to be available for on-call shifts, the frequency of which leads to further clinic postponement in order to meet the requirements of the European Working Time Directive.

The dilemma for the specialty is whether it should opt out of general medical on-call commitments. I would urge the specialty to seize the opportunity of providing increased responsibility for acute general medicine takes. Emergency admission units will continue to increase in size with increased rates of admission and the necessity to meet fourhour waiting times in accident and emergency departments. A need for cardiology and gastroenterology specialties to be available to provide 24-hour availability for emergency procedures makes it challenging for these specialties to also contribute to acute medical post-take rounds. Diabetes specialists are regularly exposed to cardiovascular, renal and neurological complications and an ongoing exposure to general medicine facilitates our understanding of these complications. Acute medical takes continue to provide the opportunity for diagnostic challenges outside the specialty which should be relished.

Winocour et al report that 377 specialist trainees in diabetes and endocrinology are due to complete their training over the next five years. I believe that for employment to be available for these trainees we should welcome the need for contributing to acute general medical takes, especially as diabetes care increasingly shifts to the community. It is equally important that the specialty is safeguarded and that time for commitment to endocrinology and diabetes as a specialty is recognised in future job plans.

AUGUSTIN BROOKS Specialist Trainee (ST4) Diabetes and Endocrinology Torbay Hospital

\section{Trends in hospital admissions for pulmonary embolism}

Editor - Aylin et al demonstrate that pulmonary embolism (PE) is an increasingly common cause for admission in NHS hospitals in England (Clin Med August 2008 pp 388-92). This poses a significant challenge in the organisation of acute care for this group of patients. Implementation of strategies for ambulatory care programmes is essential to limit the burden on inpatient resources. However, with a mortality of $10 \%$ for primary PE and a markedly higher risk in the over 75 s, identifying safe strategies is paramount.

Although recommended by the British Thoracic Society, outpatient management of low-risk PE has not been generally adopted. ${ }^{1}$ A number of risk scores have been developed to identify those suitable for outpatient management. We have analysed 100 randomly selected cases of the last 200 admissions to our hospital with a primary diagnosis of $\mathrm{PE}$ to assess the feasibility and potential advantages of implementing outpatient treatment strategies for low-risk PE. 
Using the Pulmonary Embolism Severity Index (PESI) we found that up to $43 \%$ of patients with PE would be eligible for outpatient treatment. ${ }^{2}$ As suggested by Aylin et al, age was significantly different in the low-risk and high-risk groups, 55 years and 77 years respectively $(p<0.001)$. In the lowrisk group 30-day mortality was 0 compared with $6.5 \%$ in the high-risk group. We calculated that employing an outpatient treatment strategy for low-risk PE as identified by PESI, would be safe and could account for a saving of 165 bed days per year at our district general hospital.

With growing pressure on inpatient resources the increasing rates of admission for PE could be safely cut by around $40 \%$ using entirely clinically based risk stratification indexes, to identify patients for outpatient management.

J LANDY

C BAYLISS

West Middlesex University Hospital

\section{References}

1 British Thoracic Society Standards of Care Committee Pulmonary Embolism Guideline Development Group. BTS guidelines for the management of suspected acute pulmonary embolism. Thorax 2003:58:470-83.

2 Aujesky D, Perrier A, Roy PM et al. Validation of a clinical prognostic model to identify low-risk patients with pulmonary embolism. J Intern Med 2007;132:24-30.

\section{Stranger on the shore - a personal view}

Flying into London at night is one of the most beautiful sights, especially when seen for the first time through the eyes of a nineyear-old child arriving from Pakistan. To me it is as beautiful today as it was in 1959 when we first landed on these shores.

The view remains forever etched in my memory and even as I prepare to attend my first dinner at the Royal College of Physicians (RCP), having recently been made an Honorary Fellow, it all flashes before me again as I gaze out through the windows of my Canary Wharf penthouse and see the lights of London sparkling below me.

I walk into the classroom to be faced with a sea of white faces. I am a stranger on the shore, a shore which has seen very few strangers. A welcome, words of kindness, a gentle enquiry and a wish to share their world with me makes me feel very special. A welcome given to a special guest, 'Where do you come from?', 'Come sit next to me', 'Be my best friend?'. The school bell rings and I start my first day at school in Peckham, London.

I walk into the main hall at the RCP. I am a stranger on this shore. The hall is packed with the great and the good; notaries dressed with regalia each symbolising some part of the college's history, distinguished veterans of the College, dinner-jacketed and at ease with the events of the evening as though it were their own private dinner party. I am welcomed as a stranger - the face of the College is wise and old and mainly male. I am welcomed, hosted and escorted to my seat, introduced to guests on my right and left and made to feel the full welcome and hospitality given to a new guest.

I reflect how the landscape has changed in the schools over the last 50 years - who welcomes who now? The Bhangra, the Bollywood, and a concoction of Eastern food feasts seem to be the norm now in many school events - the welcome for the stranger on the shore is gone. Neighbours treat each other as outsiders, the humanity that binds each of us is forgotten somewhere in a dim past.

I look around at the College and reflect. What will the landscape be like here in the next 50 years? What will become of this house of ancient customs?

YASMIN DRABU Medical Director Barking, Havering \& Redbridge Hospitals NHS Trust

\section{Clinical \& Scientific letters}

Letters not directly related to articles published in Clinical Medicine and presenting unpublished original data should be submitted for publication in this section. Clinical and scientific letters should not exceed 500 words and may include one table and up to five references.

Inflammatory rheumatic conditions and cardiovascular disease

Inflammatory rheumatic diseases have been clearly linked to premature and accelerated coronary vascular disease (CVD). ${ }^{1,2}$ This is thought to arise through the effects of systemic inflammation on lipid profile, insulin resistance, endothelial dysfunction and hypercoagulability, as well as the effects of physical deconditioning as a result of disability and the adverse effects of treatment. ${ }^{3,4}$ There has also been recent focus on the role of $\mathrm{C}$-reactive protein (CRP) and leptin as possible mediators of atherosclerosis in patients with systemic inflammation. ${ }^{4}$

It is therefore important for the rheumatologist to identify and treat modifiable cardiac risk factors. The objective of this audit was to investigate the frequency of cardiac risk factor monitoring in rheumatology outpatients, and to identify which patients had an appropriate record of preexisting cardiac risk factors.

\section{Method}

Over a two-week period the medical records of 70 patients attending the rheumatology clinic at Charing Cross Hospital, London, were examined for evidence of the following standards of CVD risk factor monitoring, as suggested by Domsic et al: ${ }^{3}$

1 Weight taken and body mass index (BMI) calculated during clinic visit

2 Blood pressure measured during clinic visit

3 Lipid profile measured within one year, or six months if previously abnormal 